DOI: $10.47456 / k r k r . v 1 i 9.31784$

\title{
Metodologias ativas para o estudo de movimentos sociais no Ensino Médio
}

Active methodologies in the study of social movements in secondary school Marcelo Kunrath Silva

Brenda de Fraga Espíndula

Camila Farias da Silva

Carla Michele Rech

Eduardo Georjão Fernandes

Ivone dos Passos Maio

Luciene Andrade Lauda

Matheus Mazzilli Pereira

Resumo: O presente artigo apresenta o processo de desenvolvimento de um material didático para o estudo dos temas de movimentos sociais e ativismo, voltado a educadores do Ensino Médio. Para tanto, parte da análise das limitações nas abordagens desses temas encontradas nos livros didáticos de Sociologia. A partir disso propõe - com base em conceitos estruturantes tais como, confronto político, movimentos sociais e contramovimentos, e na construção de um quadro de princípios orientadores pedagógicos que privilegiem experiências ativas de aprendizado - formas complementares de tratar o tema. O resultado é a proposição de um material didático complementar, com foco em situações didáticas para serem aplicadas em sala de aula, cujo processo envolveu criação, pesquisa e aplicações piloto em sala de aula.

Palavras-chave: material didático; ensino médio; movimentos sociais; ativismo; metodologias ativas

Abstract: This paper presents the process of developing didactic material for the study of social movements, aimed at high school teachers. For this, part of the analysis of the limitations in the approaches to this theme found in the sociology textbooks. From that, it proposes - based on structural concepts such as "political confrontation", "social movements" and "countermovements", and on the construction of a framework of pedagogical guiding principles that privilege active learning experiences complementary ways of dealing with the theme. The result is the proposal of didactic material which focus is practical didactic classroom situations. The process of conception of the material involved creativity, research, and experimental experiences in classroom.

Keywords: didactic material; high school; social movements; active methodologies

\section{Introdução}

Os recorrentes episódios de confronto político no Brasil apresentam um quadro de mobilizações cada vez mais complexas e multifacetadas, tais como os evidenciados com o ciclo de protestos de 2013. Estes e outros processos mais recentes têm colocado na cena pública temas importantes como a interação entre protestos, mídia e polícia, as relações entre movimentos sociais 
e as instituições políticas, as táticas de ação dos ativistas e a crescente relação do ativismo político com as redes sociais digitais.

Esta realidade tem incentivado debates sobre a temática dos movimentos sociais e do ativismo nas salas de aula de Ensino Médio no Brasil, desafiando pressupostos teóricos sobre a mobilização coletiva e tornando mais complexos os processos de ensino e aprendizagem sobre essa temática. Nesse contexto, como parte do projeto de pesquisa "Transformações do Ativismo no Brasil: junho de 2013 em perspectiva comparada"1, cujo principal objetivo era compreender os impactos do ciclo de protestos de 2013 sobre as dinâmicas da mobilização coletiva no Brasil, estava previsto o desenvolvimento de um material didático sobre os temas do ativismo, da ação coletiva e dos movimentos sociais direcionado aos docentes que atuam no Ensino Médio. Integrando a equipe responsável pela produção desse material didático, nos questionamos como tais temas poderiam ser tratados nas escolas e qual seria a abordagem mais adequada para compreender processos tão dinâmicos e complexos, que chegam a influenciar o próprio cotidiano das instituições escolares, como no caso das ocupações de escolas ocorridas em anos recentes (CAMPOS e MEDEIROS; RIBEIRO, 2016; PIOLLI et al., 2016; CATINI e MELLO, 2016).

Como uma das etapas necessárias, entendemos que para elaborar tal material didático seria necessário verificar anteriormente como os livros didáticos de Sociologia utilizados nas escolas abordam essas temáticas. Esta análise $^{2}$ permitiu identificar as potencialidades e lacunas dos materiais investigados, à luz das teorias contemporâneas que orientam os estudos sobre ativismo e movimentos sociais.

Também foi preciso refletir acerca de quais perspectivas pedagógicas poderiam sustentar o empreendimento de criar um material voltado a docentes do Ensino Médio, que rompesse com as abordagens tidas como conteudistas ou tradicionais. Morán (2015) identifica a primeira abordagem com a forma de

1 Projeto aprovado no âmbito do edital Memórias Brasileiras - Conflitos Sociais, com financiamento da Coordenação de Aperfeiçoamento de Pessoal de Ensino Superior CAPES, sob responsabilidade do Grupo de Pesquisa Associativismo, Contestação e Engajamento - GPACE/UFRGS.

2 Detalhes desta análise são apresentados por Pereira et al. (2019). 
ensino em que tudo é previsto antes e aplicado de forma igual para todos, ao mesmo tempo; e a segunda, por aulas expositivas e centradas na figura do professor como transmissor do conhecimento. Cano (2012) lembra que a noção da Sociologia como um grande conjunto de teorias e o destaque excessivo para os clássicos e para a erudição podem se constituir, muitas vezes, em um obstáculo epistemológico. Neste sentido, optamos por uma abordagem crítica aos modelos tidos como mais tradicionais de ensino nos filiando à perspectiva das metodologias ativas, por meio da construção de situações didáticas que promovam experiências para o aprendizado. Para tanto, nos orientamos por um conjunto de metodologias que envolve três estratégias pedagógicas que têm em comum a busca de uma aprendizagem com foco na participação e envolvimento dos estudantes: a Aprendizagem Baseada em Problemas (ABP), a Metodologia da Problematização (MP), e a Perspectiva Educativa de Projetos de Trabalho (PEPT).

Assim, o objetivo do presente artigo é apresentar o processo de desenvolvimento deste material didático sobre movimentos sociais, explicitando o exercício de transpor ideias (ou ideais) de metodologias ativas de ensino para situações didáticas práticas de sala de aula, associadas a uma abordagem relacional da Sociologia da ação coletiva, crítica às abordagens mais correntes nos livros didáticos. O material didático em questão tomou forma de um livro (em versão impressa e digital $^{3}$ ) que tem como público-alvo professores de Sociologia de Ensino Médio, mas pode ser ampliado para professores de disciplinas introdutórias de cursos de graduação ou ainda para usos em espaços de formação de ou sobre movimentos sociais, por exemplo.

O artigo está dividido da seguinte forma: na próxima seção, fazemos uma síntese das lacunas identificadas na análise dos livros didáticos de Sociologia do Ensino Médio empreendida por Pereira et al. (2019), e apontamos os caminhos teóricos escolhidos para a construção do material didático proposto. Depois, apresentamos as diferentes abordagens teóricopedagógicas que influenciaram a nossa proposição de situações didáticas que

\footnotetext{
${ }^{3}$ Acessível em https://www.ufrgs.br/gpace/pt/material-didatico/
} 
privilegiassem experiências ativas de aprendizado. Por fim, abordamos como a análise crítica dos livros e nossos referenciais teóricos e pedagógicos se expressaram efetivamente nas situações didáticas criadas, além de trazer as experiências de testagem pelas quais o material passou. $O$ trabalho é um esforço coletivo de dar relevo a uma experiência frutífera de construção de novas possibilidades de ensinar e aprender Sociologia, em especial, sobre movimentos sociais na sala de aula. Ainda que para fins de organização as etapas deste processo estejam de forma sequencial, na prática, houve um movimento dialético entre o conjunto de referências teóricas e os processos práticos desenvolvidos.

\section{Movimentos Sociais no Ensino Médio: em busca de outras abordagens}

Procurando identificar como os movimentos sociais têm sido abordados nos livros didáticos de Sociologia para o Ensino Médio, foi feita a análise de livros aprovados pelo Programa Nacional do Livro Didático (PEREIRA et al, 2019). O quadro abaixo busca sintetizar as lacunas que foram identificadas nos livros didáticos, as quais indicam abordagens que consideramos que podem ser mais bem exploradas a partir de uma perspectiva relacional e com contribuições teóricas mais atuais.

Quadro 01 - Lacunas nas abordagens dos movimentos sociais nos livros de Ensino Médio

\begin{tabular}{|c|}
\hline Dicotomia Estado / Movimentos Sociais \\
\hline Autonomia dos Movimentos Sociais como valor normativo \\
\hline Pouco espaço para as implicações da internet para a organização e mobilização da \\
ação coletiva \\
\hline Homogeneidade/ausência de conflito nos Movimentos Sociais \\
\hline Escassez de debate sobre mídia e/ou abordagem da mídia como inimiga dos \\
Movimentos Sociais \\
\hline Raro debate sobre relações globais dos Movimentos Sociais \\
\hline Pouco espaço à repressão estatal aos Movimentos Sociais \\
\hline Movimentos Sociais retratados como polo virtuoso da democracia, ausência de \\
abordagem sobre contramovimentos
\end{tabular}

Fonte: autoria própria com base em Pereira et al 2019.

Assim, tomando o desafio de construir um material didático que possa efetivamente ampliar e/ou complementar o estudo de movimentos sociais no Ensino Médio, adotamos como nosso referencial teórico abordagens relacionais sobre o tema. Isto significa que buscamos compreender os 
movimentos sociais - seu surgimento, repertórios, conquistas e derrotas como resultado de suas relações de conflito e cooperação com outros atores, que estão direta ou indiretamente ligados às suas demandas. A partir de uma perspectiva relacional, as ações dos movimentos sociais são vistas em um campo mais amplo de disputas e conflitos sobre seus interesses ${ }^{4}$.

Desta forma, destacamos como conceitos estruturantes a noção de confronto político e o par conceitual de movimentos e contramovimentos. Confrontos políticos consistem em "interações nas quais atores apresentam demandas que afetam os interesses de outros atores levando a esforços coordenados em defesa de interesses ou programas compartilhados" (TILLY; TARROW, 2015, p.7, tradução nossa). Neste sentido é estimulado que se observe os movimentos sociais com o foco para o conflito mais amplo nos quais estão inseridos, bem como suas interações com aliados, opositores e terceiros em torno de suas demandas. Determinados confrontos políticos polarizam movimentos e contramovimentos, que podem ser definidos como

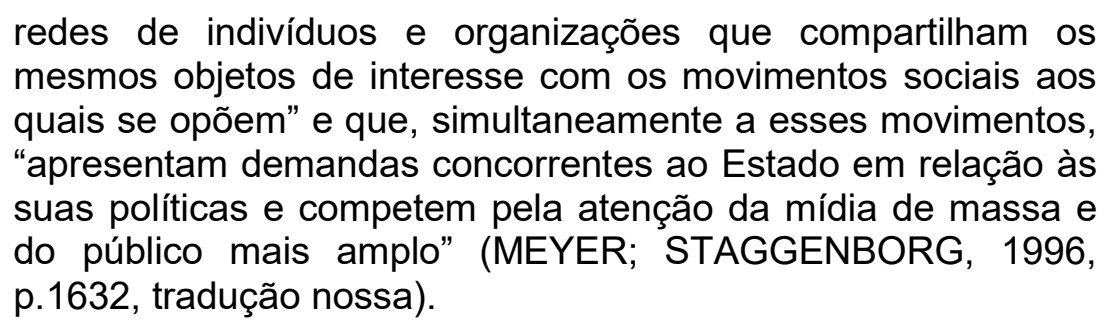

Tais conceitos estruturam o material e trazem consequências teóricas para os temas abordados. A primeira delas é que nos afastam da compreensão de que movimentos sociais são resultados espontâneos de problemas sociais ou de estruturas de dominação da sociedade. Outra consequência é não compartilhar da ideia de que movimentos sociais são respostas automáticas de grupos dotados de recursos frente a instituições que favoreçam sua ação. Entendemos que a própria construção do que é um problema social está em disputa na sociedade e que os movimentos sociais surgem quando grupos desenvolvem formas de organização, ação e interpretação do mundo em interação com outros atores sociais. Desta forma, diferentemente da tendência encontrada na análise dos livros didáticos de associar fortemente movimentos

\footnotetext{
${ }^{4}$ Barcelos, Silva e Pereira (2017).
} 
a problemas sociais e identidades vistas como preexistentes, buscamos enfatizar que movimentos, identidades coletivas e problemas sociais surgem articulados a partir de interações entre diversos atores sociais.

No que se refere à organização e à ação, buscamos dar ênfase aos processos organizativos e de construção de formas coletivas de ação para o surgimento de movimentos sociais. Já constituídos, os movimentos sociais seguem em relações de conflito e cooperação disputando temas e demandas na sociedade, que tanto podem ser pela expansão de direitos civis e sociais, como pela sua restrição. Nas disputas em que estão inseridos cabe destaque às disputas internas, ou seja, os movimentos sociais são heterogêneos e estão em processos contínuos de definição de si, dos outros e do ambiente político e social no qual atuam. Esta heterogeneidade e dinamicidade é também característica da mídia e do Estado; portanto, os movimentos sociais estão engajados em relações de conflito e cooperação também com os veículos midiáticos e com as instituições estatais. Isso nos leva a considerar que, diferente das abordagens tradicionais, nem sempre a mídia e o Estado estão em oposição às demandas dos movimentos sociais. Por último, cabe destaque às relações de conflito com o Estado ou com contramovimentos que geram repressão dos movimentos sociais. As formas de repressão ao ativismo político têm se transformado nos últimos anos, não se limitando apenas a táticas mais visíveis como o uso de tropas de choque contra manifestantes nas ruas, desenvolvendo diferentes estratégias na área de inteligência digital.

A partir da busca da superação daquilo que identificamos como lacunas nos livros didáticos e de perspectivas teóricas e conceitos que têm centralidade na literatura contemporânea de movimentos sociais e ativismo, se constituíram os oito módulos temáticos que estruturam o material didático. Estes módulos temáticos se desdobram na proposição de dezesseis situações didáticas e serão explorados na seção três deste artigo.

\section{Metodologias ativas: por um ensino relacional}

Juntamente à problematização das abordagens teóricas subjacentes aos conteúdos encontrados nos livros didáticos do Ensino Médio, o outro desafio 
que se impôs ao grupo para a formulação de um material didático complementar foi pensar sobre as práticas pedagógicas. Em outras palavras, nos deparamos com os seguintes questionamentos: Como ensinar de maneira a romper com a aula expositiva tradicional? Como ensinar Sociologia, especificamente movimentos sociais, de forma significativa para os estudantes? Como transcender ao livro texto, tradicionalmente adotado? Como trazer contribuições teóricas da literatura contemporânea para compreender os movimentos sociais, para o próprio fazer pedagógico?

Diante destes questionamentos, antes de nos filiarmos a uma proposta pedagógica específica, partimos de três metodologias ou estratégias pedagógicas que têm em comum a busca de uma aprendizagem mais ativa e criativa, com foco na participação e envolvimento dos estudantes e com maior proximidade entre professor e estudante (no sentido de flexibilizar a hierarquia do saber). Possuem ainda, forte estímulo ao trabalho em grupo e a tentativa de ampliar as relações da aprendizagem com o mundo "real". São elas: a) Aprendizagem Baseada em Problemas (ABP); b) Metodologia da Problematização (MP); c) Pedagogia de Projetos ou Perspectiva Educativa de Projetos de Trabalho (PEPT). Aqui apresentamos alguns conceitos fundamentais das três propostas e, quando possível, indicamos vantagens e desvantagens em suas implementações apontadas na literatura.

Ainda que algumas destas abordagens não reconheçam suas influências teórico-conceituais, há razoável consenso de que as três possuem influência da Escola Nova - corrente teórica surgida nas primeiras décadas do século $X X$ que buscava construir formas mais ativas de aprendizagem em oposição ao modelo vigente no período, estritamente ligado à memorização e à reprodução. A corrente escolanovista tem entre seus representantes Montessori, Decroly e Caparède, na Europa, e John Dewey, criador do Método de Projetos, nos Estados Unidos (BOROCHOVICIUS e TORTELLA, 2014; FLECK, 2007). No Brasil, há autores que reconhecem a proximidade das teorias com a Pedagogia da Libertação de Paulo Freire, em especial na busca de contextos reais e da construção ativa da aprendizagem (BERBEL, 1998). 
A literatura destaca algumas vantagens dos métodos que pressupõem que a aprendizagem é aprimorada pela interação social e é facilitada quando os estudantes são expostos a situações da vida real. Além disso, os autores entendem que a autonomia metacognitiva do/da estudante ( $O$ que devo fazer? Como farei? Funcionou?) favorece processos de aprendizagem eficazes, autorregulados e contínuos. Há ainda a defesa de que estes métodos são mais dinâmicos e prazerosos, influenciando na motivação para aprender (RIBEIRO, 2008; BERBEL, 1998, FLECK, 2007).

A Aprendizagem Baseada em Problemas surgiu na década de 1960 na Universidade McMaster no Canadá. A iniciativa de uma mudança curricular partiu da constatação de que os egressos de medicina deixavam o curso com baixa capacidade para aplicar os conteúdos conceituais na realização de diagnósticos e com poucas habilidades e atitudes profissionais desejáveis à prática médica (RIBEIRO, 2008). A ABP, conforme lembra o autor, foi popularizada a partir de 1980. Nesta formulação,

era proposto o envolvimento dos estudantes no processo de
aprendizagem de forma que fossem utilizados cenários-
problemas para instigá-los e, por meio desta, era esperado que
eles identificassem lacunas no seu aprendizado para decidir
quais informações precisavam adquirir para resolver ou
administrar a situação a que foram apresentados" (SAVIN-
BADEN e MAJOR, 2004, p.3, tradução nossa).

Os autores destacam como características básicas do modelo clássico de ABP:

- Situações reais e complexas que não tenham uma resposta certa são o foco organizador para aprender;

- Estudantes trabalham em grupos para confrontar o problema, identificar lacunas e desenvolver soluções viáveis;

- Estudantes ganham novas informações a partir da aprendizagem auto direcionada;

- Tutor age como um facilitador; os problemas levam a desenvolver capacidade (habilidades e competências) de resolver casos clínicos.

Com o passar do tempo, os conceitos da ABP foram ficando mais flexíveis e fluídos, podendo ser aplicados em todo o currículo, parcialmente (em 
uma disciplina, por exemplo) ou de forma híbrida, combinada com outras metodologias. Para Ribeiro (2008), a ABP não é uma receita, mas sim uma metodologia de contexto, de ensino-aprendizagem de conhecimentos conceituais, procedimentais e atitudinais objetivados. Porém, o autor alerta que à medida que a proposta se afasta do modelo original, pode haver perdas qualitativas dos resultados esperados do método.

Como desvantagens do método, alguns autores indicam que ele não gera precisão no conhecimento de teorias, exige mais tempo para ser desenvolvido e pode, portanto, não dar conta de conteúdos previstos, trazendo o dilema entre abrangência versus profundidade (RIBEIRO, 2008). Pode, ainda, exigir da instituição de ensino uma estrutura de recursos humanos mais ampla, uma vez que muitas vezes dependem de comissões que elaborem os problemas necessários (BERBEL, 1998). Apesar dos autores que defendem o método atestarem sua flexibilidade para ser aplicado em diversas áreas do conhecimento, em nossa pesquisa encontramos aplicação dele apenas em áreas da saúde e nas ciências exatas como Matemática e Engenharia. Este dado pode indicar certa dificuldade em aplicar o método no ensino das Ciências Sociais, uma vez que seu objetivo está sempre associado a um produto, a um saber-fazer.

Já a Metodologia da Problematização (MP), no Brasil, conforme Berbel (1995) foi difundida por Juan Diaz Bordenave e Adair Martins Pereira, no livro "Estratégias de ensino-aprendizagem", publicado pela primeira vez em 1977. Sua referência foi o Método do Arco (FREITAS, 2012), que pode ser sintetizado na tríade ação - reflexão - ação. O método dá ênfase ao seu caráter participativo e, a partir de uma visão crítica da sociedade, propõe a atuação intencional para transformá-la (BERBEL, 1998, FREITAS, 2012). Para o autor,

tem-se como objetivo a mobilização do potencial social, político e ético dos estudantes, que estudam cientificamente para agir politicamente, como cidadãos e profissionais em formação, como agentes sociais que participam da construção da história de seu tempo, mesmo que em pequena dimensão (BERBEL, 1998, p. 145).

Uma das principais diferenças entre a MP e a ABP seria que, nesta última, o estudante desenvolve um método pragmático com foco na solução de 
problemas já estabelecidos; já na MP, o estudante desenvolve a capacidade de identificar e elaborar problemas com ênfase na reflexividade, para, em seguida, apresentar suas soluções (FREITAS, 2012). Também é possível apontar que a MP não tem a pretensão de uma reconfiguração curricular como a ABP. Ela se propõe como uma metodologia que pode ser utilizada para o ensino de determinados temas de uma disciplina, nem sempre apropriada para todos os conteúdos (BERBEL, 1998). Como síntese das etapas da Metodologia da Problematização, podemos apontar:

- Observação da realidade concreta: os estudantes devem observar determinada realidade a partir de um tema ou conteúdo. As observações devem identificar dificuldades, falhas, contradições, conflitos etc., que podem configurar-se como problema. A partir desta experiência, um ou mais problemas são escolhidos pelos alunos para estudo e investigação em pequenos grupos. O professor deve facilitar a discussão, ajudando os alunos na formulação final do problema.

- Determinação de pontos-chave: os estudantes iniciam com reflexões sobre os fatores que geram o problema, produzindo uma percepção de sua multideterminação e de sua complexidade, numa dimensão social mais ampla, que, frequentemente, não está evidenciada. Juntos, buscam encaminhamentos para a sua solução. Esse é o momento da análise reflexiva em que o professor ajuda os estudantes na produção de uma nova síntese.

- Teorização: é a etapa investigativa, em que os estudantes buscam conhecimentos e informações acerca do problema e de seus pontos-chave em variadas fontes primárias ou secundárias (pesquisa bibliográfica, leitura, entrevistas, consultas a especialistas etc.). Organizam e analisam o material obtido, além de verificar sua validez e pertinência para a solução do problema.

- Hipóteses de solução: aqui são valorizadas a criticidade e a criatividade dos estudantes. A construção das hipóteses de solução deve ser guiada pela percepção do problema e pela compreensão teórica adquirida pelos estudantes.

- Aplicação prática à realidade: o caráter prático dessa etapa tem por finalidade fazer com que os estudantes ultrapassem o exercício intelectual, 
tomando decisões e executando-as, demarcando um componente social e político em sua formação e ajudando-os a desenvolverem o compromisso com a transformação da realidade observada (Adaptado de BERBEL, 1998 e FREITAS, 2012).

Os dois métodos parecem guardar muitas semelhanças. As diferenças mais destacadas se mostram na construção do problema, como já mencionado, e o caráter mais político da MP, que propõe não só a conexão com o real, mas a intervenção na realidade social.

Por último, destacamos a Pedagogia de Projetos, ou Perspectiva Educativa de Projetos de Trabalho (PEPT). Da mesma forma que as anteriores, a PETP também propõe um processo de aprendizagem mais dinâmico e dá especial atenção à questão da transdisciplinaridade, buscando romper com a prática fragmentadora das disciplinas que se estabeleceu nos currículos e nas ciências. No Brasil, essa abordagem ganha força a partir da década de 1980. Com base em Fleck (2007) ressaltamos algumas características da PEPT:

- Ruptura com o esquema tradicional de ensino por disciplinas: o recurso da divisão do saber é considerado insuficiente para enfrentar os desafios impostos hoje à construção do conhecimento, quer em âmbito geral, do desenvolvimento científico e tecnológico, quer no individual, de cada estudante, em seu processo de formação por meio do sistema de escolarização.

- Possibilidade de reunir o que já foi aprendido pelo estudante e o que pode vir a sê-lo nos vários campos do conhecimento - os projetos envolvem os saberes já acumulados pelos estudantes e todo o potencial possível de novos conhecimentos a serem adquiridos.

- Construção de conhecimento pela investigação própria dos estudantes: se o professor se preocupar em desenvolver nos estudantes uma atitude permanente de indagação, com perguntas a respeito de problemas significativos e se eles forem estimulados a buscarem respostas, haveria uma boa iniciação aos passos introdutórios da pesquisa.

- Articulação entre trabalho individual e coletivo e valorização de atitudes e comportamentos sociais: o trabalho por projetos privilegia a evolução de todo 
grupo, sem desconsiderar também o crescimento de cada um dos participantes. Busca as aprendizagens significativas.

- Combinação entre o trabalho escolar e o de várias outras instituições e agências: trabalhando com projetos, a escola multiplica as fontes de informação e de interação, seja na própria instituição como fora dela, na comunidade local, nacional e mundial, sem esquecer da mobilização possível e necessária das famílias.

Fleck (2007) afirma que a PEPT está permeada pelas questões tradicionais de um projeto: O que vamos estudar? Por quê (justificativa)? Para quê (quais habilidades e competências devem ser desenvolvidas)? Como? Quando? Quem? Quais os recursos necessários? Tais questões estão na prática tanto dos professores quanto na dos estudantes.

Essa última abordagem parece diferenciar-se das outras por não exigir a resolução de um problema. Ela indica considerar o projeto como um caminho para produzir o conhecimento, sem que seja necessária uma proposta de transformação na realidade, como na MP, ou que tenha uma solução a um problema prático, como no $\mathrm{ABP}$, dando ênfase ao processo. Aqui cabe destacar que nossa proposta não se identifica tanto com solucionar problemas, mas sim vê como fundamental instigar a problematização sociológica, ou seja, buscar desnaturalizar as concepções formadas em torno do tema dos movimentos sociais e, neste sentido, a própria concepção do que é um problema social é colocada na perspectiva de uma disputa entre os diferentes atores sociais. Além disso, essa perspectiva destaca quais habilidades e competências são desenvolvidas no projeto.

A breve revisão dessas três abordagens que se propõem a romper com métodos tradicionais de ensino nos apontou que os caminhos indicados guardam semelhanças e diferenças, mas todas trazem contribuições relevantes para a prática pedagógica. Também identificamos que todos os autores trazem a importância de pensar o contexto onde as práticas se desenvolvem, permitindo que as metodologias não sejam encaradas como receitas prontas. Nesse sentido, compartilhamos com Hernandez (2014) quando afirma que não 
é o caso de uma filiação a uma ou outra tendência, já que nos entendemos como autores e não como seguidores.

A partir da reflexão sobre estas propostas e do entendimento sobre o trabalho que estávamos construindo, nos interessava identificar quais ideias, valores e práticas poderíamos transpor para nosso material voltado a propor situações didáticas para a sala de aula. O quadro abaixo evidencia nossas escolhas do que chamamos princípios pedagógicos orientadores que sustentaram a elaboração do material didático:

Quadro 02 - Princípios pedagógicos orientadores / Metodologia pedagógica de influência

\begin{tabular}{|c|c|}
\hline Princípios pedagógicos orientadores & $\begin{array}{c}\text { Metodologia pedagógica } \\
\text { de influência }\end{array}$ \\
\hline $\begin{array}{c}\text { Aprendizagem com foco na participação e } \\
\text { envolvimento do estudante }\end{array}$ & ABP, MP, PEPT \\
\hline Trabalho em grupos ou times & ABP, MP, PEPT \\
\hline $\begin{array}{c}\text { Criar "cenários-problema" ou instigar a } \\
\text { identificação/formulação de problemas }\end{array}$ & ABP/MP \\
\hline $\begin{array}{c}\text { Estimular a reflexão sobre a complexidade e a } \\
\text { multideterminação dos problemas identificados }\end{array}$ & MP \\
\hline $\begin{array}{c}\text { Teorização, investigação, pesquisa por parte dos/das } \\
\text { estudantes }\end{array}$ & ABP, MP, PEPT \\
\hline Aplicação prática à realidade & ABP, MP \\
\hline $\begin{array}{c}\text { Articulação do trabalho escolar e o contexto } \\
\text { sociocultural dos/das estudantes }\end{array}$ & MP, PEPT \\
\hline $\begin{array}{c}\text { Conexão do trabalho escolar com outras instâncias e } \\
\text { organizações (da comunidade) }\end{array}$ & PEPT \\
\hline Identificar habilidades e competências a serem \\
desenvolvidas \\
\hline $\begin{array}{c}\text { Transdisciplinariedade e mobilização de aprendizados } \\
\text { acumulados }\end{array}$
\end{tabular}

Fonte: autoria própria

Uma vez delineadas as lacunas nas abordagens tradicionais e mapeados os princípios orientadores pedagógicos, coube ao grupo responsável pela criação do material didático, a partir dos saberes acumulados nas pesquisas de movimentos sociais e na experiência como docentes, colocar em marcha um processo criativo para elaborar propostas reais para a sala de aula. A essas propostas demos o nome de situações didáticas, no sentido de serem vivências planejadas para gerar aprendizado, sem, contudo, serem inflexíveis às adaptações contextuais de cada realidade escolar - uma situação sempre deixa caminhos, escolhas para quem as experimenta - ou seja, não 
está acabada. Cabe esclarecer que não há relação direta com a Teoria das Situações Didáticas de Brousseau (2008), ainda que sua ideia de lançar mão de um dispositivo (ou jogo) que desafie os estudantes e, neste processo, possam descobrir por si mesmos as respostas (relacionadas a teorias matemáticas) seja uma boa referência para pensar propostas de práticas de ensino. A experiência e o resultado da elaboração do material didático estão na próxima seção.

\section{Livro de Situações Didáticas - os movimentos sociais na sala de aula}

O material didático desenvolvido, cuja versão final está disponível online gratuitamente por meio de uma plataforma virtual, apresenta além da introdução aos debates teóricos que orientam sua formulação, um glossário de conceitos mobilizados em tais debates. Seu foco, no entanto, está na proposição de metodologias ativas de ensino - situações didáticas (SD) - a serem utilizadas pelos docentes para desenvolver, junto aos estudantes, habilidades e competências relacionadas ao objetivo geral do material.

O objetivo geral do material didático é ofertar diferentes estratégias de aula que apresentem aos estudantes elementos do debate teórico contemporâneo sobre movimentos sociais, contramovimentos e confrontos políticos e que os ajudem a compreender essas dinâmicas de forma a embasar um posicionamento reflexivo e autônomo sobre conflitos sociais e protestos no Brasil contemporâneo. Nesse sentido, o material didático tem os seguintes objetivos específicos: a) evidenciar os confrontos políticos em torno da ordem e da mudança social, da democracia e dos direitos humanos; b) provocar reflexões sobre o papel da organização e das identidades coletivas para o fenômeno da mobilização; c) evidenciar as disputas interpretativas em torno dos significados dos movimentos sociais na mídia e entre os próprios ativistas; e d) debater as relações de confronto e cooperação estabelecidas entre movimentos sociais, partidos, governos e Estado.

Os objetivos específicos se desdobraram em oito módulos temáticos, cada um dos módulos deve desenvolver uma habilidade específica sempre relacionada ao objetivo geral do material didático e propõe duas situações 
didáticas relacionadas à sua temática. Como produto, há dezesseis situações didáticas propostas (quadro 03), que não são sequenciais, nem hierarquizadas; ou seja, os educadores poderão aplicá-las de forma independente, considerando o planejamento do ano letivo. As situações didáticas têm tempo de execução variado, de um a três encontros de 45/50 minutos. E todas disponibilizam na seção material de apoio os recursos necessários à sua execução, facilitando, desta forma, sua aplicação em escolas que possuem poucos recursos.

O quadro abaixo sintetiza as habilidades a serem desenvolvidas pelas situações didáticas, tendo como referência os módulos temáticos.

Quadro 03 - Temas, módulos e habilidades a serem desenvolvidas pelas situações didáticas

\section{MOVIMENTOS SOCIAIS E SOCIEDADE}

\begin{tabular}{|c|c|}
\hline $\begin{array}{l}\text { MÓDULO } 1 \text { - Movimentos Sociais- } \\
\text { Ordem e Mudança Social }\end{array}$ & $\begin{array}{l}\text { MÓDULO } 2 \text { - Movimentos Sociais, } \\
\text { Democracia e Direitos Humanos }\end{array}$ \\
\hline $\begin{array}{l}\text { Habilidades Desenvolvidas: } \\
\text { Desnaturalizar processos de } \\
\text { mudança social, reconhecendo a } \\
\text { importância dos movimentos sociais } \\
\text { e da ação contestatória para tais } \\
\text { processos. }\end{array}$ & $\begin{array}{l}\text { Habilidades Desenvolvidas: Analisar } \\
\text { experiências de } \\
\text { mobilização coletiva, refletindo se e como tais } \\
\text { experiências de mobilização contribuíram para a } \\
\text { construção de uma sociedade democrática e } \\
\text { igualitária. }\end{array}$ \\
\hline SD 1.1 - Desafios da Vida & $\begin{array}{l}\text { SD } 2.1 \text { - Tanta gente sem casa, tanta casa } \\
\text { sem gente. }\end{array}$ \\
\hline SD 1.2 - Chocar para Mudar & SD 2.2 - Distopias \\
\hline \multicolumn{2}{|c|}{ DOS PROBLEMAS AOS MOVIMENTOS SOCIAIS } \\
\hline $\begin{array}{l}\text { MÓDULO } 3 \text { - Movimentos Sociais, } \\
\text { Problemas e Identidades }\end{array}$ & $\begin{array}{c}\text { MÓDULO } 4 \text { - Movimentos Sociais, Organização } \\
\text { e Mobilização }\end{array}$ \\
\hline $\begin{array}{l}\text { Habilidades Desenvolvidas: } \\
\text { Desnaturalizar a "indignação" } \\
\text { coletiva, reconhecendo a } \\
\text { importância dos movimentos sociais } \\
\text { nas disputas em torno dos } \\
\text { problemas sociais e das identidades } \\
\text { coletivas. } \\
\end{array}$ & $\begin{array}{l}\text { Habilidades Desenvolvidas: Reconhecer a } \\
\text { importância dos processos de organização } \\
\text { coletiva para o surgimento da mobilização, } \\
\text { refletindo sobre as potencialidades das diversas } \\
\text { formas de organização. }\end{array}$ \\
\hline SD 3.1 - Viajantes no Tempo & SD 4.1 - Por trás da "espon \\
\hline $\begin{array}{c}\text { SD 3.2 - Embalando Corações e } \\
\text { Mentes }\end{array}$ & SD12 Oranizarn Mabilizar \\
\hline \multicolumn{2}{|c|}{ MOVIMENTOS SOCIAIS EM DISPUTA } \\
\hline $\begin{array}{l}\text { MÓDULO } 5 \text { - Heterogeneidade dos } \\
\text { Movimentos Sociais }\end{array}$ & MÓDULO 6 - Movimentos Sociais e Mídia \\
\hline $\begin{array}{l}\text { Habilidades Desenvolvidas: } \\
\text { Identificar disputas e divergências } \\
\text { internas aos protestos e movimentos } \\
\text { sociais, refletindo sobre os diversos } \\
\text { posicionamentos existentes. }\end{array}$ & $\begin{array}{l}\text { Habilidades Desenvolvidas: Contextualizar } \\
\text { historicamente e relacionalmente o uso da } \\
\text { violência por movimentos sociais, Estado e seus } \\
\text { adversários. }\end{array}$ \\
\hline SD 5.1 - Eu e os Feminismos & SD 6.1 - Um Protesto, Duas Versões \\
\hline
\end{tabular}




\begin{tabular}{|c|c|}
\hline SD 5.2 - Gincana dos 20 centavos & SD 6.2 - Memeativismo \\
\hline \multicolumn{2}{|c|}{ MOVIMENTOS SOCIAIS E ESTADO } \\
\hline $\begin{array}{c}\text { MÓDULO 7 - Movimentos Sociais } \\
\text { como Política }\end{array}$ & MÓDULO 8 - Movimentos Sociais, Violência e \\
Repressão
\end{tabular}

Fonte: autoria própria

É importante destacar que todas as situações didáticas introduzem a temática a partir de uma pergunta disparadora, com o objetivo de nortear a ação e encaminhar o desenvolvimento das habilidades. Assim, a ideia é que cada situação didática porte problemas relacionados a temáticas empiricamente situadas, que estimulem o desenvolvimento das habilidades relacionadas ao módulo, ao mesmo tempo em que apresentem potência para relacionar-se com outros temas da Sociologia, bem como com outras disciplinas do currículo. As situações didáticas são, portanto, apresentadas a partir da seguinte estrutura:

Quadro 04 - estrutura das situações didáticas

Objetivos: os objetivos a serem alcançados com a atividade desenvolvida. Conceitos relevantes: os conceitos que dão base teórica às atividades (definições no Glossário que acompanha o material didático).

Tempo Total Estimado: tempo estimado para a realização da atividade. Procedimentos: os procedimentos necessários para a realização da atividade que, por sua vez, são divididos em quatro elementos: temática mobilizadora;

pergunta disparadora que introduz os estudantes ao tema e estimula o início das discussões em sala de aula;

as atividades propriamente ditas a serem realizadas;

uma sugestão de fechamento ao docente que provoque entre os estudantes reflexões sobre as atividades realizadas;

Materiais de apoio: materiais que podem ser utilizados para o desenvolvimento da situação didática (se necessário).

Mais Sociologia: apresenta aos docentes possíveis conexões entre as temáticas trabalhadas na situação didática e outras temáticas do componente curricular Sociologia.

Projeto Interdisciplinar: apresenta aos docentes propostas de projetos de ensino e pesquisa a serem realizados em conjunto com outros componentes curriculares, tomando a situação didática como um estímulo inicial para a realização destes projetos. 
O processo de elaboração das situações didáticas foi realizado por meio de trabalho de pesquisa e de criação em equipe, cujos membros partilham experiências no tema dos movimentos sociais e em docência no Ensino Médio e Superior. $\mathrm{Na}$ sua maioria, as situações didáticas foram concebidas individualmente pelos integrantes do grupo, de acordo com o interesse e o conhecimento de cada um nas temáticas propostas nos módulos. Posteriormente, cada situação didática elaborada se tornava objeto de discussão ao ser apresentada ao grande grupo, tendo como referência tanto o objetivo geral e os pressupostos teóricos e pedagógicos orientadores do material, quanto as habilidades específicas a serem desenvolvidas e as concepções questionadas pelo módulo ao qual se reportava.

A partir do momento em que um primeiro conjunto de situações didáticas foi formulado, o projeto passou a ser apresentado a professores que ministram aulas de Sociologia no Ensino Médio em escolas estaduais do Rio Grande do Sul, e a estudantes universitários vinculados aos núcleos de Ciências Sociais do Programa Institucional de Bolsas para Iniciação à Docência (PIBID/CAPES) da UFPEL e da UFRGS, entre outros parceiros ${ }^{5}$. Esses educadores foram convidados a realizar aplicações piloto das atividades propostas no material junto a turmas de Ensino Médio de escolas estaduais localizadas em Pelotas e em Porto Alegre. O objetivo dos testes junto às escolas parceiras era obter o retorno desses profissionais sobre a aplicação do material didático que estava sendo produzido, de forma que o resultado dessas experiências fornecesse ao grupo subsídios para aprimorar as propostas que vinham sendo elaboradas.

A estratégia desenvolvida para atingir esse objetivo incluía, além de encontros regulares entre o grupo proponente e as escolas parceiras, acompanhamento presencial de algumas aulas/testes e a aplicação de uma ficha de avaliação ${ }^{6}$ para cada situação didática trabalhada em sala de aula.

5 IFSUL Sapucaia e IFRS Restinga, por iniciativa de dois professores que mantinham afinidades com o grupo de pesquisa, também participaram das aplicações/testes.

${ }^{6} \mathrm{~A}$ ficha de avaliação é composta por questões que visam mensurar a eficácia da situação didática na prática em sala de aula: 1) se o tempo previsto para a atividade foi suficiente; 2) a pertinência do material de apoio; 3 ) se a proposta da atividade foi bem compreendida pela turma; 4) quais dúvidas surgiram durante a prática - estudantes e/ou professores; 5 ) se a turma se envolveu na atividade proposta; 6 ) se o objetivo foi atingido, se desenvolveu as habilidades 
Essa dinâmica que envolvia dois processos distintos, porém interligados pesquisa e criação do material de atividades e o retorno dos profissionais sobre a percepção dos estudantes da prática em sala de aula - resultou em um fluxo de informações compartilhadas entre o grupo proponente e os profissionais das escolas colaboradoras do projeto. Desta forma, à medida que novas situações didáticas eram finalizadas, novas reuniões aconteciam com educadores e pibidianos $^{7}$, e novas agendas de aplicações eram delineadas em acordo com o programa da disciplina de Sociologia ${ }^{8}$ de cada escola.

A escolha de qual situação didática seria experimentada em sala de aula, de uma maneira geral, ficou a cargo dos educadores e pibidianos responsáveis pela disciplina de Sociologia. Assim, dentre as escolhidas, uma se destacou e foi a mais aplicada9: SD 1.1 - Desafios da Vida, referente ao módulo 1 Movimentos Sociais - Ordem e Mudança Social. Esse cenário que possibilitou que a mesma situação didática fosse aplicada diversas vezes para diferentes turmas, embora não tenha sido a intenção inicial do projeto, veio ao encontro de nossos objetivos e tornou-se a experiência que propiciou reunir o maior número de informações pertinentes à avaliação a qual nos propúnhamos, sendo esse o motivo pelo qual a tomamos como modelo neste estudo de forma a ilustrar o processo e o resultado dos testes realizados.

A dinâmica elaborada na situação didática "Desafios da Vida" propõe um jogo de tabuleiro, cujas cartas distribuídas apresentam cenários possíveis sobre os seguintes temas: educação, emprego, habitação, cultura, esporte, saúde, transporte e segurança. As cartas dos baralhos distribuídos - sem que os estudantes saibam - apresentam vantagens para um grupo e desvantagens para o outro, ou seja, cartas "boas"10 e cartas "ruins". O objetivo é que a partir

propostas, se refletiu sobre as concepções questionadas; 7 ) as reflexões dos alunos sobre o tema; 8) espaço livre para as considerações que se fizerem necessárias.

${ }^{7}$ Termo utilizado para se referir aos estudantes de graduação vinculados ao Programa Institucional de Bolsas para Iniciação à Docência (PIBID/CAPES).

${ }^{8}$ De uma maneira geral, o tema dos Movimentos Sociais é abordado nos segundos e terceiros anos das escolas estaduais de ensino médio.

${ }^{9}$ Esse fato ocorreu pela opção do PIBID/UFPel em aplicar a mesma Situação Didática para várias turmas.

10 Exemplo de cartas referente à temática do emprego: Carta "boa" - Não era bem o que você queria, mas uma boa vaga de trabalho na empresa do seu tio não poderia ser negada. Avance 1 casa!. Carta "ruim" - Apesar de você ser a funcionária mais antiga e com melhor formação, foi 
do momento em que os participantes em desvantagem percebam a diferença e se manifestem, o educador intervenha sugerindo que as cartas sejam embaralhadas e que o jogo recomece. Esse é o momento, portanto, em que deve iniciar entre os estudantes o debate para decidirem se realizam essa operação ou não. Independentemente da decisão tomada, o jogo deve continuar.

Ao final do jogo a turma deve discutir o que levou à decisão final. Tal embate abre a possibilidade de discussão sobre a forma que diferentes grupos sociais interpretam a realidade como sendo justa ou injusta. As respectivas leituras refletirão em posicionamentos de manutenção da ordem simbolicamente representados pela opção de não embaralhar as cartas - e aqueles que buscam a mudança e a transformação da realidade que vivem pela opção de embaralhar as cartas e recomeçar o jogo. No entanto, a dinâmica não se restringe a essa problemática. É possível também revisitar as situações expostas nas cartas, debatendo o que elas revelam da estrutura social em que se desenrolam e quais seriam as diferentes estratégias de lidar com tais situações em um país como o Brasil, fortemente marcado pela desigualdade social.

Abaixo apresentamos um quadro que indica a relação que a situação didática testada estabelece com a temática do módulo ao qual pertence, com a lacuna identificada na análise dos livros didáticos, além de destacar os princípios orientadores pedagógicos mobilizados em sua prática e apontar as concepções questionadas e as habilidades a serem desenvolvidas.

Quadro 05 - Cruzando a dinâmica da Situação Didática com os Princípios Pedagógicos Orientadores

\section{Situação Didática: 1.1. Desafios da Vida}

Objetivo: Identificar a existência de disputas em torno da manutenção ou transformação das estruturas sociais.

Temática: A situação didática parte de um jogo de tabuleiro que reproduz situações comuns do cotidiano do brasileiro. Ao longo do jogo, os estudantes percebem que alguns jogadores possuem vantagens para dar conta dos desafios, enquanto outros se veem presos por sua condição social desprivilegiada.

Projeto Interdisciplinar: Criação de um baralho informativo - dados sobre situações cotidianas que retratam a desigualdade social vigente no país.

Relações com o módulo 1: Movimentos Sociais, Ordem e Mudança Social

o seu colega quem foi promovido. Antes disso, quando ainda estavam no mesmo nível hierárquico, ele ganhava mais do que você! Volte 1 casa! 


\begin{tabular}{|c|}
\hline $\begin{array}{c}\text { Habilidades desenvolvidas: Desnaturalizar processos de mudança social, } \\
\text { reconhecendo a importância dos movimentos sociais e da ação contestatória para tais } \\
\text { processos. }\end{array}$ \\
\hline Concepções Questionadas: "A sociedade muda/se mantém naturalmente" \\
Relação com as lacunas identificadas nos livros didáticos \\
\hline Movimentos Sociais retratados como "polo virtuoso" da democracia \\
\hline Princípios orientadores pedagógicos evidenciados na SD \\
\hline $\begin{array}{c}\text { Aprendizagem com foco na participação dos estudantes; trabalho em grupos ou } \\
\text { times; reflexão sobre a multideterminação dos problemas identificados; Investigação } \\
\text { por parte dos estudantes; articulação com a realidade local - escolar e comunitária; } \\
\text { transdisciplinariedade. }\end{array}$ \\
\hline
\end{tabular}
Fonte: autoria própria.

A partir das experiências realizadas em sala de aula foi possível observar que, embora as turmas tenham apresentado reações distintas, o objetivo da prática foi atingido. A problemática central, que visava identificar a existência de disputas em torno da manutenção ou transformação das estruturas sociais foi compreendida e debatida com sucesso. Para ilustrar tal afirmação, elencamos a seguir algumas considerações com base no retorno obtido por meio das fichas de avaliação preenchidas pelos educadores, e pela observação/participação de integrantes do grupo de pesquisa nas práticas:

a) a grande maioria dos estudantes se envolveu na atividade justificando o jogo como uma dinâmica diferente de uma aula "tradicional";

b) embora em momentos distintos, em todas as turmas os grupos em desvantagem, ao percebê-la, se manifestaram;

c) a discussão prevista se desenrolou: alguns estudantes se recusavam a embaralhar as cartas, outros acreditavam que embaralhar não resolveria a situação e, ainda, alguns sugeriram que as cartas "boas" e "ruins" deveriam ser distribuídas igualmente e o jogo recomeçar;

d) houve identificação de grande parte dos participantes, que se relaciona à condição socioeconômica predominante entre estudantes de escolas públicas, com as cartas "ruins". Tal identificação se expressou na criação de novas cartas por parte dos estudantes, cujas situações apresentadas eram baseadas em suas experiências pessoais de carências e injustiças;

e) as reflexões dos estudantes se desenrolaram, principalmente, em torno da questão da injustiça social presente em nossa sociedade: 
desigualdade social, mazelas do sistema público de saúde, desigualdade salarial e de oportunidades entre homens e mulheres, problemas de moradia, exploração do sistema capitalista e a questão racial. Também houve casos em que surgiu o debate clássico da Ciência Política sobre a natureza humana (Hobbes e Locke);

f) houve debate sobre a relevância dos movimentos sociais na transformação da realidade, destacando seu papel na problematização de situações tidas como naturais, bem como na mobilização da sociedade para buscar mudanças. Neste ponto, cabe ressaltar a reflexão de que tais movimentos organizados por mudança muitas vezes enfrentam contramovimentos que se organizam no sentido de manter a ordem.

A etapa dos testes das situações didáticas e a troca com professores e estudantes foram fundamentais para reforçar a pertinência da proposta idealizada: seu tempo de realização, sua capacidade de mobilização e sua potência para o desenvolvimento das habilidades escolhidas. Em muitos casos, essas vivências permitiram que as situações didáticas fossem ajustadas para que melhor cumprissem com os objetivos almejados. Além disso, as diversas discussões entre o grupo proponente e os envolvidos nas aplicações piloto resultaram no entendimento da necessidade da criação de um site que comportasse o material didático em plataforma aberta, possibilitando, dessa maneira, novas formulações de situações didáticas por parte dos usuários.

\section{Considerações finais}

Pensar a relação de ensino-aprendizagem e transpor tais reflexões para propostas concretas para a sala de aula é um esforço que muitas vezes acaba sendo negligenciado no ensino das Ciências Sociais. Este trabalho buscou jogar luz neste processo. Num primeiro momento, situou como as temáticas dos movimentos sociais e do ativismo vêm sendo abordadas nos livros didáticos de Ensino Médio; a partir disso, apontou lacunas teóricas dessas abordagens a partir dos acúmulos contemporâneos das pesquisas nas temáticas em foco. Em seguida, após uma reflexão crítica quanto aos modos tradicionais de ensino, na linha da transmissão de conteúdo, buscou apresentar 
alternativas abordando três metodologias ativas e criativas de ensino pautadas por maior interação entre os estudantes, menor hierarquia na relação professor-aluno e conexão com o mundo real. A partir daí, o grande esforço desse estudo residiu em expor o processo de criação do material didático, para o estudo dos movimentos sociais (e temas afins), com foco na proposição de situações didáticas voltado a docentes de Sociologia de Ensino Médio.

Dentre o conjunto de procedimentos adotados na elaboração desse material, alguns merecem destaque. O primeiro deles, certamente, é a oportunidade propiciada pela extensão universitária, no sentido que possibilita que a produção intelectual saia dos muros da universidade, de modo que o diálogo seja ampliado com outros atores. Prova disso, foi o trabalho realizado em conjunto com as escolas de Ensino Médio e com o PIBID/CAPES, cuja colaboração foi fundamental para a viabilização do projeto, principalmente no que concerne ao feedback das metodologias ativas que vinham sendo elaboradas, por meio das situações didáticas testadas em sala de aula. $O$ segundo aspecto a ser destacado é a importância da realização de um trabalho em moldes colaborativos. O pressuposto teórico-pedagógico de que a produção do conhecimento ganha qualidade ao ser coletivizada foi adotado pelo grupo proponente em todas as etapas do processo.

Como limitação desta etapa, apontamos o fato de não ter sido possível a testagem de todas as situações didáticas criadas, como previsto inicialmente, devido ao limite de tempo determinado pelo próprio projeto. Entretanto, a ideia de hospedar o livro digital em site com possibilidade de avaliação e sugestão de usuários possibilita que o processo de crítica, de adaptação e de ressignificação do material tenha continuidade por meio das reflexões e possíveis colaborações de outros professores e estudantes.

Por fim, é importante ressaltar a potência que o material possui como provocação para a criação de metodologias ativas que abordem outras temáticas da Sociologia, para além dos movimentos sociais, tal como apontado em cada uma das situações didáticas na seção "Mais Sociologia", na qual são destacadas conexões possíveis com diferentes áreas ou temas da disciplina. 


\section{Referências}

BARCELOS, Marcio; SILVA, Marcelo K.; PEREIRA, Matheus M. Redes, campos, coalizões e comunidades: conectando movimentos sociais e políticas públicas. BIB, n.82, p.13-40, 2016.

BERBEL, Neusi A. N. Metodologia da problematização: uma alternativa metodológica apropriada para o Ensino Superior. Semina, v.16, n.2, Ed. Especial, p.9-19, 1995.

BERBEL, Neusi A. N. A problematização e a aprendizagem baseada em problemas: diferentes termos ou diferentes caminhos? Interface - Comunic., Saúde, Educ., v.2, p.139-154, 1998.

BOROCHOVICIUS, E.; TORTELLA, J. C. B. Ensaio: Avaliação e Políticas Públicas em Educação. Rio de Janeiro, v.22, n. 83, p. 263-294, abr./jun. 2014.

BROUSSEAU, G. Introdução ao estudo das situações didáticas: conteúdos e métodos de ensino. São Paulo: Ática, 2008.

CAMPOS, Antonia M.; MEDEIROS, Jonas; RIBEIRO, Márcio M.. Escolas de Luta. São Paulo: Veneta, 2016.

CANO, Ignácio. Nas Trincheiras do Método: o ensino da metodologia das Ciências Sociais no Brasil. Sociologias. POA, v. 14, n. 31, p. 94-119, 2012.

CATINI, Carolina e MELLO, Gustavo C. M. Escolas de luta, educação política. Educação \& Sociedade. v. 37, n. 137, p. 1177-1202, 2016.

FLECK, Maria Luiza S. Pedagogia por projetos: o princípio, o fim e o meio. Diálogo, n.11, p.117-140, 2007.

FREITAS, R. A. M. M.. Ensino por problemas: uma abordagem para o desenvolvimento do aluno. Educação e Pesquisa (USP. Impresso), v. 38, p. 403-418, 2012.

HERNANDEZ, F. Entrevista concedida. Revista Bem Legal, Vol. 4, No. 1 2014. Disponível em: http://www.ufrgs.br/revistabemlegal/edicoesanteriores/no 1 2014/entrevista-com-o-professor-fernando-hernandez. Acesso em: 21.09.2019.

MEYER, David S.; STAGGENBORG, Suzanne. Movements, countermovements, and the structure of political opportunity. American Journal of Sociology, v. 101, n. 6, p. 1628, 1996.

MORÁN, José. Mudando a educação com metodologias ativas. Coleção Mídias Contemporâneas. Convergências Midiáticas, Educação e Cidadania: aproximações jovens, v. 2, p. 15-33, 2015.

PEREIRA, Matheus M.et al. Movimentos sociais no ensino médio: uma análise dos livros didáticos de Sociologia. In: CONGRESSO BRASILEIRO DE SOCIOLOGIA, 19., 2019, Florianópolis. Anais[...].Florianópolis, 2019. 


\section{Disponível}

em:https://www.sbs2019.sbSociologia.com.br/atividade/hub/gruposdetrabalho.

Acesso em: 16.07.2019.

PIOLLI, E., PEREIRA, L. e MESKO, A. A proposta de reorganização escolar do governo paulista e o movimento estudantil secundarista. Crítica Educativa. v.2, n.1, 2016.

RIBEIRO, Luis Roberto de Camargo. Aprendizagem baseada em problemas (PBL) na educação em Engenharia. Revista de Ensino de Engenharia, v. 27, n. 2, p. 23-32, 2008.

SAVIN-BADEN, M. e MAJOR, C. H. Foundations of Problem-based Learning. New York, Open University Press, 2004.

TILLY, Charles; TARROW, Sidney. Contentious politics. 2nd ed. New York: Oxford University Press, 2015.

\section{Sobre os autores}

\section{Marcelo Kunrath Silva}

mksilva@ufrgs.br

Licenciado em História pela Universidade Federal do Rio Grande do Sul (UFRGS), mestre e doutor em Sociologia pela mesma universidade. Possui pós-doutorado no Watson Institute for International Studies/Brown University. Desde 1999 é professor do Departamento de Sociologia da UFRGS, integrando o Programa de Pós-Graduação em Sociologia. Coordena o Grupo de Pesquisa Associativismo, Contestação e Engajamento - GPACE.

\section{Brenda de Fraga Espíndula}

bespindula@gmail.com

Licenciada em Ciências Sociais e mestre em Sociologia pela UFRGS. Atualmente, doutoranda do mesmo programa e pesquisadora-ativista em laboratórios de inovação cidadã. Interesses de pesquisa em tecnologias digitais, ativismos, movimentos sociais e participação política. Membro do Grupo de Pesquisa Associativismo, Contestação e Engajamento - GPACE.

\section{Camila Farias da Silva}

camilafsb@yahoo.com.br

Licenciada e bacharel em ciências sociais pela Universidade Federal do Rio Grande do Sul (UFRGS). Mestre e doutoranda em sociologia (PPGS/UFGRS). Faz parte do Grupo de Pesquisa Associativismo, Contestação e Engajamento. Atualmente é professora de sociologia no Colégio Técnico Industrial de Santa Maria, da Universidade Federal de Santa Maria (CTISM/UFSM). 


\section{Carla Michele Rech}

carlatsul@yahoo.com.br

Licenciada e Mestre em Ciências Sociais pela Universidade Federal de Pelotas (UFPel). Doutora em Sociologia (UFRGS). Professora substituta do Curso de Licenciatura em Ciências Sociais do Departamento de Sociologia e Política da UFPel (2018-2020). Professora voluntária do Núcleo de Ciências Sociais/Filosofia PIBID/CAPES da UFPEL (2018/2019). Integrante do Grupo de Pesquisa Associativismo, Contestação e Engajamento (GPACE/UFRGS).

\section{Eduardo Georjão Fernandes}

eduardo.g.fernandes@gmail.com

Doutor em Sociologia pela Universidade Federal do Rio Grande do Sul (UFRGS). Professor do Centro Universtiário Uniftec. Membro do Grupo de Pesquisa Associativismo, Contestação e Engajamento (GPACE/UFRGS).

\section{Ivone dos Passos Maio}

zimaio@gmail.com

Doutoranda em Sociologia (UFRGS), bacharel em Turismo (PUCRS) e em Ciências Sociais (UFRGS). Como docente possui experiência no ensino superior e técnico. Membro do Grupo de Pesquisa Associativismo, Contestação e Engajamento (GPACE/UFRGS).

\section{Luciene Andrade Lauda}

lulauda09@gmail.com

Licenciada e Bacharel em Ciências Sociais (UFRGS). Mestre e Doutora em Sociologia (UFRGS). Como docente possui experiência no Ensino Superior e Médio.

\section{Matheus Mazzilli Pereira}

matheus.mazzilli@gmail.com

Professor e pesquisador do Programa de Pós-Graduação em Sociologia Política da Universidade Vila Velha (PPGSP/UVV). Doutor em Sociologia pela Universidade Federal do Rio Grande do Sul (UFRGS). Membro do Grupo de Pesquisa Associativismo, Contestação e Engajamento (GPACE). 